\title{
Domestic water meter accuracy
}

\author{
J. A. du Plessis \& J. J. Hoffman \\ Department of Civil Engineering, Faculty of Engineering, \\ University of Stellenbosch, South Africa
}

\begin{abstract}
The accuracy of water meters is a fundamental component of the sustainability of all water supply related services provided by municipalities, as one of their core functions. An appropriate water meter audit provides a starting point on which a proper water meter management plan needs to be based. The replacement of these meters can be an expensive exercise and the accuracy, taking ageing into consideration, is of critical importance. The research presented in this paper focuses on the possible influence that ageing might have on the accuracy of domestic water meters. The paper also provides key pointers for a useful water meter audit to enable an appropriate water meter management plan.

The research results clearly show that ageing does have an impact, but that most of the old meters tested under laboratory conditions, still provide surprisingly accurate results despite their long operational lifetime (20+ years). The losses incurred as a result of these inaccuracies needs to be weighed carefully against the financial cost of a meter replacement program with a 10 year replacement interval. Keywords: water meter audit, water meter accuracy, domestic water meter, water meter replacement, water meter management plan.
\end{abstract}

\section{Introduction}

South Africa is a land with unevenly distributed water resources and huge climatic differences. According to the United Nations [1], a country can be considered to be water stressed if the available resources are less than $1,700 \mathrm{~m}^{3}$ per person per year. Southern Africa's estimated available water resources are only $1,289 \mathrm{~m}^{3} \mathrm{per}$ person per year which clearly puts it in a water stressed scenario. In general terms, South Africa can be classified as an arid or semi-arid region, with $21 \%$ of the country receiving less than $200 \mathrm{~mm} /$ year, while $44 \%$ receives between 200 and $500 \mathrm{~mm} /$ year $[2,3]$. 
Based on a number of possible water demand scenarios in South Africa, Turton and Henwood [4] stated that serious water supply issues can be expected from 2025 onwards. The importance of the need for the effective management of the water resources is therefore obvious.

While different approaches and methods exist to define and to explain the appropriate management of water resources, Water Conservation (WC) and Water Demand Management (WDM) remain key focus points. The National Water Act [5] highlights the importance of effective WC and WDM, while the "Water Conservation and Water Demand Management Strategy for the Water Sector" [6] highlights a number of national goals and objectives (see table 1).

Table 1: National WC/WDM objectives.

\begin{tabular}{|c|c|}
\hline Objective & Description of Objectives \\
\hline 1 & $\begin{array}{l}\text { To facilitate and ensure the role of WC/WDM in achieving } \\
\text { sustainable, efficient and affordable management of water } \\
\text { resources and water services }\end{array}$ \\
\hline 2 & $\begin{array}{l}\text { To contribute to the protection of the environment, ecology and } \\
\text { water resources }\end{array}$ \\
\hline 3 & $\begin{array}{l}\text { To create a culture of WC/WDM within all water management } \\
\text { and water services institutions }\end{array}$ \\
\hline 4 & To create a culture of WC/WDM for all consumers and users \\
\hline 5 & $\begin{array}{l}\text { To support water management and water services institutions to } \\
\text { implement WC/WDM }\end{array}$ \\
\hline 6 & $\begin{array}{l}\text { To promote the allocation of adequate capacity and resources by } \\
\text { water institutions }\end{array}$ \\
\hline
\end{tabular}

Regulations relating to Compulsory National Standards and Measures to Conserve Water [7] and the associated guidelines [8] were issued by the Department of Water and Sanitation (DWS) under Sections 9(1) and 73(1)(j) of the Water Services Act [9]. These regulations deal with far more than only the issues pertaining to WDM, but only the latter will be highlighted here.

The guidelines [8] address a number of important water management and water metering issues, related to water metering for municipalities. Water services audit are required which stated that water services development plan needs to include the quantity of water services provided, meter installation and testing data and WC and WDM data. All supply points must be equipped with a measuring device or a flow control device and all metering devices must comply with national standards.

It is clear from the national goals as provided in table 1 and the guidelines discussed above, that the main objective of WDM is to minimise water loss and consequently water metering plays a key role in this process.

Accurate data forms the basis of effective WDM, but accurate data can only be available if proper measurements take place. At municipal level, these 
measurements depend on a well-established metering system. While the accuracy of these water meters is the focus of the research presented in this paper, an understanding of the availability and physical condition of these meters is first required.

\section{Household water meters}

Household connections provide the interface between the end-user and the distribution system, and they also provide reliable data on which the billing system depends. Water meters can be considered as the most basic building blocks of any data collection system, and therefore it is important to take note of some of the typical problems associated with household meters and the reading thereof.

Typical problems as highlighted by du Plessis [10] include incorrectly sized meters (with a too large meter, low flows will not be measured accurately), incorrect readings from the dial and meters installed incorrectly.

Further problem areas related to metering include the administrative problems associated with the handling of the metering data within a municipality. Meter readings are considered to be a financial issue and are therefore managed by the financial departments in most municipalities. The technical departments, however, need this data for proper planning and to ensure that effective water usage can be implemented. There is typically however not a well-established working relationship between the financial and technical (water) departments within most municipalities.

Proper metering results in the understanding of the water situation within a municipality and forms the basis of the water audit. The first step in this process of ensuring proper meter reading is an appropriate water meter audit.

\section{The water meter audit}

An appropriate water meter audit provides, among other information, a "snap shot" of the situation of the metering system at a municipal level. To be able to provide usable data, it is important to collect a significant amount of data in a systematic manner and make the collected data available in an easy way to be used for further decision making. It is therefore also important to carefully consider the data that need to be collected and a typical set of information that might be collected is presented in table 2 . The data can be collected in various ways, but the use of an electronic device with GPS data capturing functions can provide an easy platform.

It is important that all the collected data are linked to its specific plot or property and while various methods might be used, the use of a unique $21 \mathrm{SG}$ code proves to be very valuable for further calculations and linkages within the municipality. The 21SG code created and used to link each set of data consists of different fields of data as summarised in table 3 .

This code can be used to link the data collected in the field with the data set provided by the financial department for comparison reasons for most municipalities. 
Table 2: Summary of data collected.

\begin{tabular}{|l|l|}
\hline Data required & Description \\
\hline ID & Unique number generated automatically \\
\hline Latitude/Longitude & GPS - Position \\
\hline Erf number & From maps provided to operators \\
\hline Water meter installed & Yes/No? \\
\hline Leakage & Visible leakages, classified as wet, drip or water? \\
\hline Serial No. & For meter \\
\hline Date on meter & If available \\
\hline Diameter & $15,20,25,50$ mm \\
\hline Meter box & Options provided: None, standard, built \\
\hline Location & Meter inside or outside the property boundaries? \\
\hline Installation 1 & Meter above or below ground level? \\
\hline
\end{tabular}

Table 3: $21 \mathrm{SG}$ code composition.

\begin{tabular}{|l|l|}
\hline Digits used (number) & Description \\
\hline $1-2(2)$ & Provincial reference $($ Western Cape =CO) \\
\hline $3-4(2), 5-8(4)$ & Area Code, Town Code \\
\hline $9-16(8), 17-21(5)$ & Erf number, Sub-division of farm \\
\hline
\end{tabular}

Once a database is available and linked to a specific plot and set of financial information, a number of different queries can be used to enable management decisions. These management decisions also need to be made based on an assumption that the data is accurate. One very important aspect in the process of verifying this assumption is to ensure that the meters are still providing accurate and reliable data.

\section{Water meter accuracy}

The accuracy of calculations for water meters depends on various factors and it is therefore required that tests be conducted under controlled laboratory conditions. Baker et al. [11] provide an overview of the complexity of such a test process and facility in order to ensure accurate evaluations. It is, however, not only just the testing procedure that might be difficult to maintain, but Herschy [12] provides the complexity involved with the interpretation of the test results.

In South Africa meter accuracy is regulated through the South African National Standards (SANS) 1529. In simple terms SANS 1529 allows for a minimum permissible relative error for new meters in the so called lower zone of $5 \%$, while the error in the upper zone is limited to $2 \%$. Van Zyl [13] provides a 
comprehensive overview and the key aspects to be considered in South Africa when managing water meters. He defines the relative error as the difference between the actual volume measured through the meter and the volume registered by the meter, expressed as a percentage of the actual volume. This relative error and the allowable limits, depending on the flow rate (and class of meter), are illustrated graphically in figure 1 . The allowable values for the different flows $\left(\mathrm{q}_{\min }, \mathrm{q}_{\mathrm{t}}\right.$ and $\left.\mathrm{q}_{\mathrm{s}}\right)$ are provided in SANS 1529 and depend on the accuracy or classification (class A, B, C and D, with D the most accurate) required (purpose) for the meter under discussion.

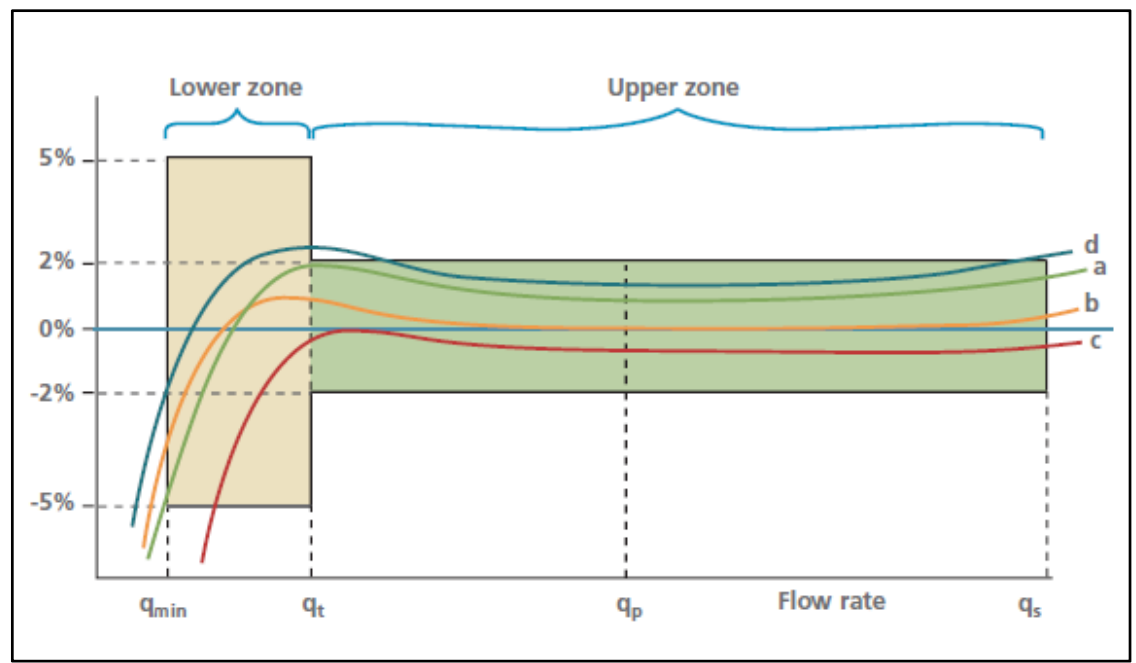

Figure 1: Relative accuracy graph [13].

Pressure also plays an important role in the testing of the accuracy of meters and SANS 1529 provides the guidelines for the testing of new water meters. According to SANS 1529 this pressure needs to be 3 times the working pressure (assumed to be $1600 \mathrm{kPa}$ ), but must be between 4,000 and 6,000 $\mathrm{kPa}$ [13].

The influence of installation errors might also result in inaccurate flow measurements. In this regard it is important to adhere to the different manufacturers' specifications. While this paper will not report on the result of the test associated with inaccurate installations, the typical experimental procedures will be discussed and an overview in the water meter audit will be provided on the number of water meters found to be installed incorrectly for a typical municipality.

\section{Data collection}

The work conducted in this research consists of two main components. Firstly a water meter audit was done and secondly the accuracy of water meters, but specifically focused on the effect of ageing on the accuracy of the meters, was researched. 
To illustrate the value of an appropriate water meter audit, almost 11,000 meters within the Witzenberg Municipal area were visited and data were collected. The data collected from these meters were linked with the financial system and the GIS system, which provide for an opportunity to make informed management decisions.

While SANS 1529 provides guidelines for the testing of new meters, the research presented in this paper focuses on the practical risks associated with the flow measuring with a typical $15 \mathrm{~mm}$ diameter domestic water meter at typical flow and pressure conditions, whether these fall within the SANS 1529 specifications or not. It was also realised that, as highlighted before, the testing of the flow meters according to SANS 1529 can be very expensive if done according to the specifications. The results, therefore, need to be evaluated within these limitations.

For the purpose of testing the inaccuracies of domestic water meters due to ageing and installation errors, a number of tests were conducted in the water laboratory at the University of Stellenbosch. A total of 91 meters were removed during routine meter replacement programs and collected for testing purposes by two different municipalities, one providing 37 while the other provided 54 meters. The 91 water meters were selected from a bigger sample size provided, after those with visible leaks were rejected for the purpose of this study.

These meters were tested at a flow rate and pressure considered to be typical for household purposes. The flow rates were achieved with the aid of ball valves using the municipal pressure which was recorded as $380 \mathrm{kPa}$, which is slightly lower than the recommended minimum pressure stipulated by SANS 1529. The flow rates used varied between 0.9 and $1.8 \mathrm{~m}^{3} / \mathrm{h}$, which compares well with similar tests done by Mukheibir et al. [14]. All the meters tested had a design flow of $1.5 \mathrm{~m}^{3} / \mathrm{h}$. With an accepted meter class rating of $\mathrm{C}$ according to SABS 1529 , the transitional zone (see $\mathrm{q}_{\mathrm{t}}$ in figure 1 ) occurs at $0.0225 \mathrm{~m}^{3} / \mathrm{h}$, which is significantly lower than the test flow range.

\section{Experimental set-up to test meter accuracy}

The main objective of the research was to quantify the expected losses due to meter inaccuracies. Water meter inaccuracies were tested by using a new $15 \mathrm{~mm}$ diameter KSM meter (the meter with the highest occurrence in the water meter audit), after volumetric verification of its accuracy at high $\left(1.8 \mathrm{~m}^{3} / \mathrm{h}\right)$ and low $\left(0.9 \mathrm{~m}^{3} / \mathrm{h}\right)$ flows. The new meter (now referred to as the Control meter) was found to be very accurate, with \% accuracy varying between $0.02 \%$ (low flow) and $0.001 \%$ (high flow) based on the volumetric tests.

All the meters tested in the laboratory were class $\mathrm{C}$ meters. For the purpose of evaluating the accuracy-age relationship, water meters were only tested at one specific flow rate and not evaluated over the full flow range spectrum. The flow rate at which all the meters were tested falls within the upper zone and depend on the local available pressure, which was not controlled, but monitored. For the purpose of this research, the test pressure can be assumed to be relatively constant at $380 \mathrm{kPa}(38 \mathrm{~m})$, which can be considered as a typical household pressure. 
For the purpose of testing the impact of ageing on the accuracy of water meters supplied by the municipalities, each meter was tested against the volume recorded by the Control meter. Each meter was tested at least 4 times and average values were used in the analysis.

To limit the number of tests to be conducted, three meters were installed in series with the Control meter first (figure 2). Flow was controlled through a set of 2 ball valves at the outlet and the pressure was logged to ensure that a constant pressure was maintained throughout the test. Although it was known that there will be a pressure drop after each of the flow meters, the emphasis was on the flow rate achieved with the setting of the ball valves. The pressure drop between meters was assumed to be small enough to be ignored for this purpose.

The age of the tested meters was determined through a code classification printed on the meters. It was however never possible to determine for how long the meters tested were actually used, since the manufacturing date was derived from the code printed on the meter and no information was available on the installation date. It is possible that a meter manufactured 20 years ago and tested as such, was only installed for, say, 3 years. It was therefore also considered to be of value to record the actual volume that was recorded over the life span of each meter tested.

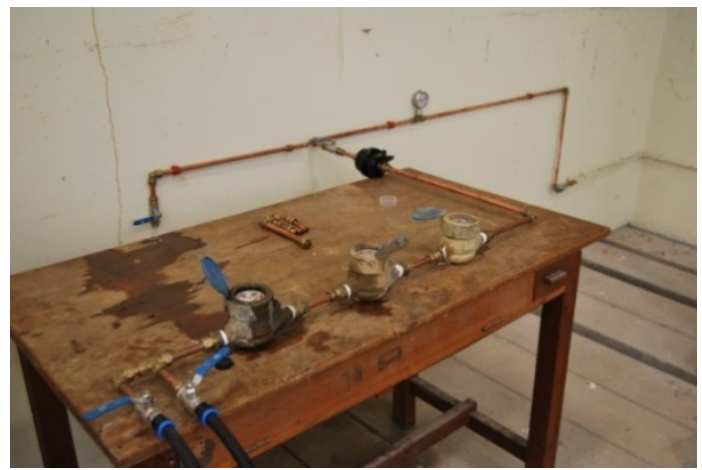

Figure 2: $\quad$ Test setup for ageing impacts.

\section{Results}

The research results achieved in the study will be presented separately for the water meter audit and the water meter accuracy tests.

\subsection{Results: Water meter audit}

While a full range of possible queries (as indicated in table 2) could be done based on the collected data during the water meter audit, only a few examples will be illustrated for the Witzenberg case study area. In the case study, approximately 11,000 meters were evaluated. 
With the $21 \mathrm{SG}$ code it was possible to use the GIS system to provide a visual overview of the collected information. Figure 3 illustrates the age distribution of installed meters.
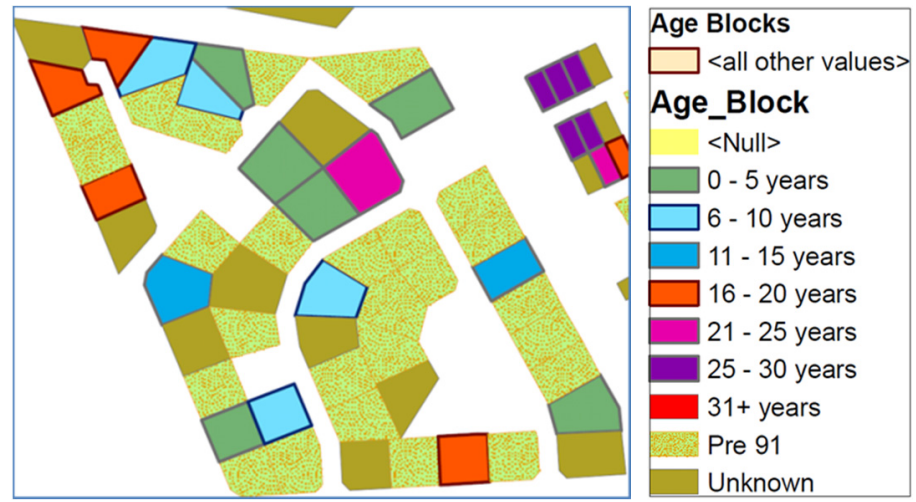

Figure 3: Water meter age distribution.

Figure 4 provides a summary of the typical results, showing the presence of various leaks at the meters and the presence of isolation valves at the meters.

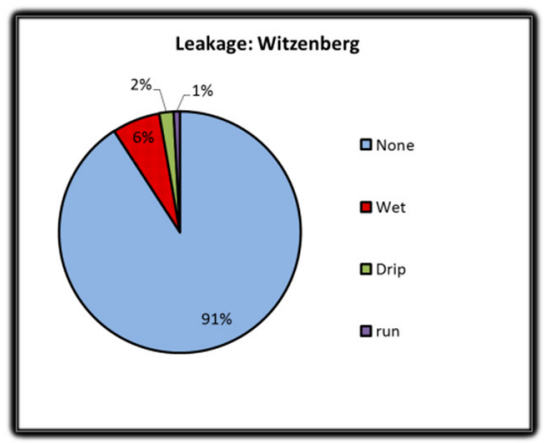

Isolation valves present at the water meter: Witzenberg

Figure 4: Summary of water meter audit.

\subsection{Results: water meter accuracy}

The difference between the volume recorded through the Control meter and the volume recorded by the 91 meters used in this analysis was expressed as a percentage of the volume recorded by the Control meter (actual), which was then plotted firstly against the age of the meter and then secondly against the volume recorded by the meter as presented in figure 5 and figure 6 respectively. The meters provided by the two different municipalities were labelled differently. 


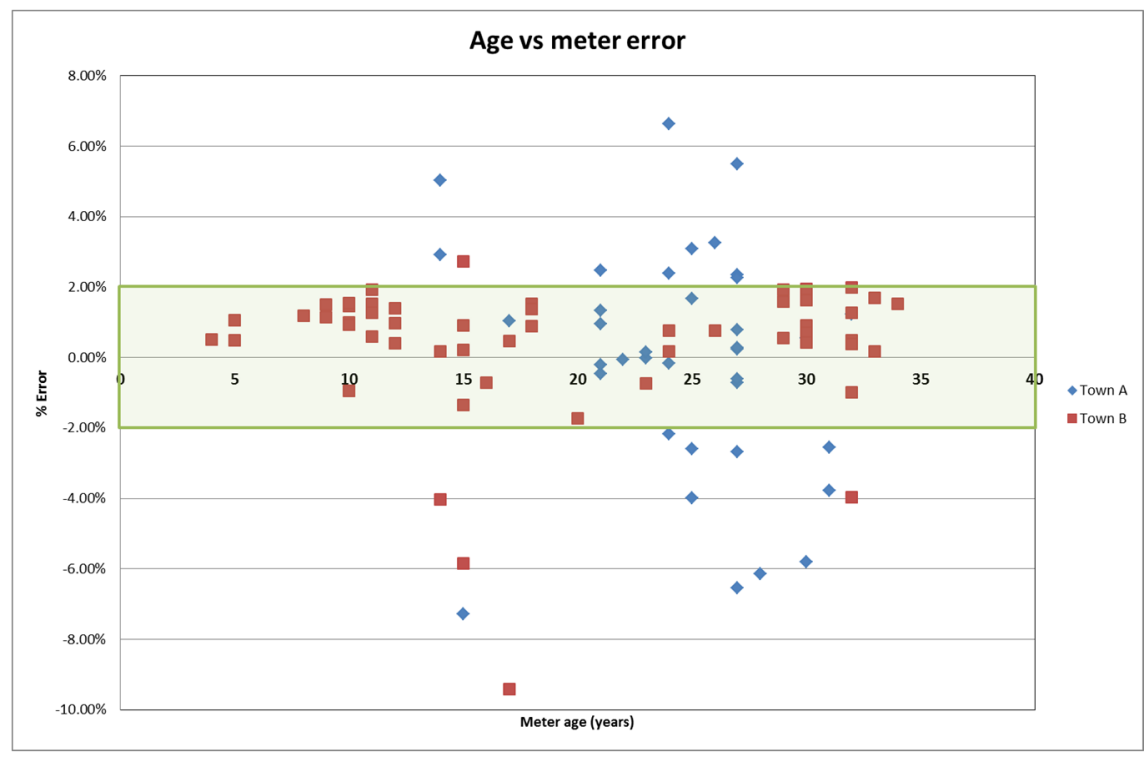

Figure 5: Percentage error vs. age.

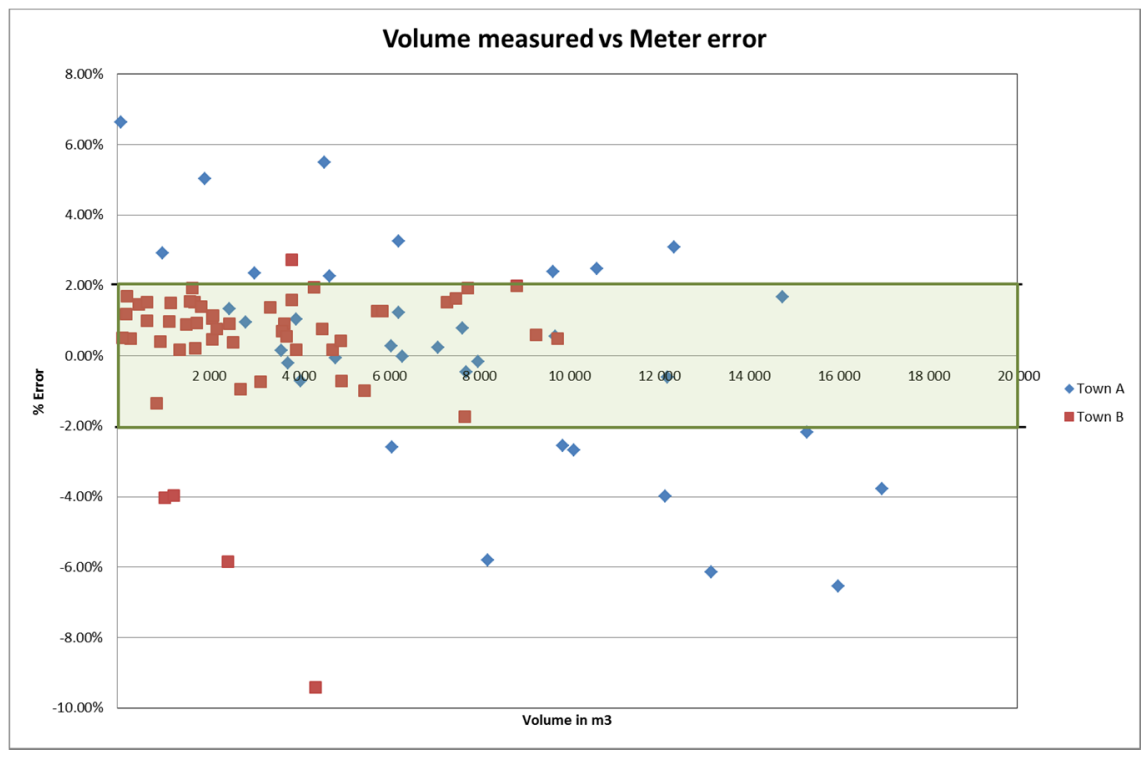

Figure 6: Percentage error vs. volume measured.

From figure 5 it is clear that the majority (71.5\%) of the 91 meters tested falls within the $2 \%$ accuracy requirement as stated in SANS 1529 for a new class C meter. Only approximately $9 \%$ of the meters 20 years and younger did test outside the $2 \%$ accuracy band. This figure increased to approximately $29 \%$ for meters 30 
years and younger. $8.8 \%$ of the meters tested as an "over register" and $8.8 \%$ tested as an "under register" for those meters falling between the $2 \%$ and $5 \%$ error band. Only one of the 91 meters tested recorded an error (under register) larger than $10 \%$ (not plotted on the graph). In total $69 \%$ of the meters over registered.

The age distribution of the 91 meters tested is presented in table 4 .

Table 4: Age distribution.

\begin{tabular}{|c|c|c|c|c|c|c|c|}
\hline Age in years & $0-5$ & $6-10$ & $11-15$ & $16-20$ & $21-25$ & $26-30$ & $30+$ \\
\hline Total & 3 & 8 & 18 & 8 & 19 & 23 & 12 \\
\hline
\end{tabular}

It is interesting to note from figure 6 that 80 out of the 91 meters tested recorded $10,000 \mathrm{~m}^{3}$ or less water. Of these 80 meters, $79 \%$ tested within the $2 \%$ accuracy band. Less than $10 \%$ of the meters tested with a recorded volume of $4,000 \mathrm{~m}^{3}$ and less tested outside the $2 \%$ accuracy band. This figure increased to $24 \%$ for meters which recorded $10,000 \mathrm{~m}^{3}$ or less. Although a very small sample size, 9 of the 11 meters with more than $10,000 \mathrm{~m}^{3}$ on their dials, recorded volumes outside the $2 \%$ accuracy band. These meters predominantly under record the volumes.

The distribution of the volume measured over the lifetime for the 91 meters is presented in table 5 .

Table 5: Volume distribution.

\begin{tabular}{|c|c|c|c|c|c|c|c|c|c|}
\hline Volume in $\mathrm{m}^{3}$ & $\frac{8}{8}$ & $\begin{array}{l}8 \\
0 \\
i \\
i \\
8\end{array}$ & $\begin{array}{l}8 \\
8 \\
\text { i } \\
1 \\
8 \\
0 \\
\text { i }\end{array}$ & $\begin{array}{l}8 \\
8 \\
+ \\
\text { + } \\
8 \\
\text { m }\end{array}$ & $\begin{array}{l}8 \\
8 \\
i \\
1 \\
8 \\
8 \\
+\end{array}$ & 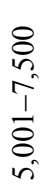 & $\begin{array}{l}8 \\
8 \\
0 \\
1 \\
1 \\
0 \\
n \\
n\end{array}$ & $\begin{array}{l}8 \\
8 \\
10 \\
1 \\
8 \\
0 \\
0\end{array}$ & $\begin{array}{l}+ \\
\stackrel{+}{8} \\
\text { in }\end{array}$ \\
\hline Number of meters & 10 & 14 & 10 & 12 & 10 & 12 & 12 & 7 & 4 \\
\hline
\end{tabular}

\section{Conclusions}

Water meters play a critical role in the management of the available water resources in any municipality and the financial implications in the event of something going wrong can be significant. Municipalities do not always have the funding available to ensure that their metering system is in optimal operational condition. The need to have a good understanding of the availability of their water meters and the condition thereof is, therefore, extremely important. A water meter audit can provide valuable information to enable effective management decisions.

The accuracy of the water meters, once their condition has been confirmed with an appropriate water meter audit, can provide further information to enable appropriate expenditure. The testing of water meters is a very expensive and time consuming process and it is therefore important to at least have a general idea of the levels of inaccuracies expected to be encountered. Working within the limitations of a detailed control over the pressure and variability of flow during 
the test procedure, the testing of ninety-one meters gives a clear indication that a typical South African household water meter is remarkably accurate even after a life span of 20 years or after having measured $4,000 \mathrm{~m}^{3}$ of water.

\section{Acknowledgements}

The authors would like to thank the Witzenberg, Stellenbosch and Overberg Municipalities for agreeing that information can be made available and for providing old water meters for testing purposes.

\section{References}

[1] United Nations Population Fund (UNPF). The State of the World Population, United Nations Population Fund Report, Online. http://www.unfpa.org/swp/2001/english/index.html

[2] Department of Water Affairs and Forestry (DWAF), National Water Resource Strategy. Our blue print for survival. National Department of Water Affairs and Forestry, First Edition, 2004.

[3] Thompson, I., National Water Resources and Catchment Management Strategy. Department of Water Affairs. Presented at Water Resource Management Course 13-16 August 2007, University of Stellenbosch, 2007.

[4] Turton, A. and Henwood, R., Hydropolitics in the Developing World. A Southern African Perspective. African Water Issues Research Unit, Centre for International Political Studies, University of Pretoria, Pretoria, 2002.

[5] Republic of South Africa (RSA), National Water Act. (Act No 36 of 1998). Pretoria, Government Printer, 1998.

[6] Department of Water Affairs and Forestry (DWAF), Water Conservation and Water Demand Management Strategy for the Water Sector. National Department of Water Affairs and Forestry, August 2004.

[7] Department of Water Affairs and Forestry (DWAF), Regulations under the Water Services Act, (Act 108 of 1997), Regulations Relating to Compulsory National Standards and Measures to Conserve Water. Government notice 22355, Pretoria, 2001.

[8] Department of Water Affairs and Forestry (DWAF), Guidelines for Compulsory National Standards and Norms and Standards for Water Services Tariffs, Pretoria, 2002.

[9] Republic of South Africa (RSA), Water Services Act (Act No 108 of 1997). Pretoria, Government Printer, 1997.

[10] du Plessis, J.A., Integrated water demand management for local water governance. PhD Dissertation, University of Stellenbosch, October 2010.

[11] Baker, R.C., Wanga, T, Moore, P.I. \& Nurse, A., Observations on the design and development of a water flow rig related to calibration in the manufacturing process. Flow Measurement and Instrumentation, 17, pp. 171-178, 2006.

[12] Herschy, R.W., The uncertainty in a current meter measurement. Flow Measurement and Instrumentation, 13, pp. 281-284, 2002. 
208 Water and Society III

[13] Van Zyl, J.E., Introduction to integrated water meter management. Water Research Commission: TT490/11, 2011.

[14] Mukheibir, P., Stewart, R.A., Giurco, D., O’Halloran, K., Understanding non-registration in domestic water meters. Australian Water Association, 39(8), pp. 95-100, 2012. 